\title{
Kinetics and Mechanism of Silver(I)-Catalyzed Oxidation of Tryptophan by Platinum(IV) in Perchlorate Solutions
}

\author{
Ahmed Fawzy ${ }^{1,2,}$, Ismail Althagafi ${ }^{1}$ \\ ${ }^{1}$ Chemistry Department, Faculty of Applied Science, Umm Al-Qura University, Makkah, Saudi Arabia \\ ${ }^{2}$ Chemistry Department, Faculty of Science, Assiut University, Assiut, Egypt
}

Email address:

afsaad13@yahoo.com (A. Fawzy), ithagafi@uqu.edu.sa (I. Althagafi)

\section{To cite this article:}

Ahmed Fawzy, Ismail Althagafi. Kinetics and Mechanism of Silver(I)-Catalyzed Oxidation of Tryptophan by Platinum(IV) in Perchlorate Solutions. American Journal of Chemical Engineering. Vol. 4, No. 1, 2016, pp. 23-29. doi: 10.11648/j.ajche.20160401.14

\begin{abstract}
The kinetics of oxidation of tryptophan by platinum(IV) was investigated in aqueous perchlorate solutions in the presence of silver(I) catalyst at a constant ionic strength of $2.0 \mathrm{~mol} \mathrm{dm}^{-3}$ and at $25^{\circ} \mathrm{C}$. The progress of the reaction was followed spectrophotometrically. The reaction did not proceed in the absence of the catalyst. The catalyzed reaction exhibited a first order dependence on both $\left[\mathrm{Pt}^{\mathrm{IV}}\right]$ and $\left[\mathrm{Ag}^{\mathrm{I}}\right]$ whereas the order with respect to tryptophan concentration was found to be less than unity. Increasing ionic strength and dielectric constant was found to decrease the oxidation rate. The suggested oxidation mechanism involves formation of a silver(I)-tryptophan intermediate complex in a pre-equilibrium step, which confirmed by both spectral and kinetic evidences. The complex reacts with the oxidant by an inner-sphere mechanism leading to decomposition of the complex in the rate-determining step. The final oxidation products of tryptophan were identified as the corresponding aldehyde (indole-3-acetaldehyde), ammonium ion and carbon dioxide.
\end{abstract}

Keywords: Tryptophan, Catalyzed-Oxidation, Silver(I), Platinum(IV), Kinetics, Mechanism

\section{Introduction}

Study of amino acids is one of the most exciting fields of organic chemistry. They play a significant role in a number of metabolic reactions like biosynthesis of polypeptide, protein and nucleotides. Thus, the mechanism of analogous nonenzymatic chemical processes in the oxidation of amino acids is a potential area for intensive investigation [1-18] in order to understand some aspects of enzyme kinetics. Tryptophan (Trp) is an essential amino acid in the human diet. It finds extensive application as a reducing agent in chemical and biochemical systems. Oxidation of tryptophan has previously been studied in acid media by few reagents, such as permanganate [4], vanadium [5], hexacyanoferrate(III) [8] and chromate [9], and in alkaline media by diperiodatocuprate(III) [6] and hexacyanoferrate(III) [7].

The chemistry of biologically active platinum(IV) complexes has increased interest in the last decades due to their remarkable anticancer properties [19-22]. Kinetic studies on the oxidation of inorganic and organic substrates using platinum(IV) complexes in the form of hexachloroplatinate(IV), $\left[\mathrm{PtCl}_{6}\right]^{2-}$, are scarce and limited to a few cases $[10-16,23-25]$, in which $\left[\mathrm{PtCl}_{6}\right]^{2-}$ may behave as one or two electron oxidant, depending upon the substrate and experimental conditions. The knowledge of the reactivity of platinum(IV) compounds towards their reduction by potential bioreductant like tryptophan may be important for understanding the mechanism of where antitumor activity as well as for designing new compounds with the least side effect.

Kinetic investigations on the oxidation reactions of amino acids catalyzed by different metal ions are an important field of chemistry due to the role played by metals in biological systems. An extensive literature survey revealed no report on the mechanistic studies of oxidation of tryptophan by platinum(IV) in either absence or presence of a catalyst. The present study deals with the title reaction in attempt to explore the kinetics and mechanistic aspects of such catalyzed reaction in strong acid medium as well as the catalytic activity of $\mathrm{Ag}^{\mathrm{I}}$.

\section{Experimental}

\subsection{Materials}

Reagent grade chemicals and doubly distilled water were used throughout the work. A stock solution of tryptophan was prepared afresh by dissolving the amino acid sample (E. Merck) in bidistilled water. Chloroplatinic acid solution 
(Johnson Matthey) was used without further purification. Required solution of the oxidant was freshly prepared before each experiment by proper dilution of its original solutionwhich is standardized spectrophotometrically [26]. The solution was stored in a bottle away from light and restandardized periodically.

\subsection{Kinetic Measurements}

All kinetic investigations were conducted under pseudofirst-order conditions where tryptophan was present in a large excess over that of platinum(IV). The ionic strength, $I$, of the reaction mixture was adjusted to 2.0 moldm $^{-3}$ using sodium perchlorate as an inert electrolyte. The reaction temperature $\left(25^{\circ} \mathrm{C}\right)$ was controlled within $\pm 0.1^{\circ} \mathrm{C}$ unless stated otherwise. The reaction was initiated by rapid addition of known amounts of the pre-equilibrated $\mathrm{Pt}^{\mathrm{IV}}$ to the reaction mixture containing the required amounts of the amino acid, perchloric acid, silver(I) nitrate, sodium perchlorate and water, thermostated at the same temperature. The solutions were then mixed and transferred to a cell with a path length of 1 $\mathrm{cm}$. The course of the reaction was followed spectrophotometrically by monitoring the decrease in the absorbance of $\mathrm{Pt}^{\mathrm{IV}}$ at $\lambda=261 \mathrm{~nm}$, its absorption maximum, as a function of time using Shimadzu UV-VIS-NIR-3600 double-beam spectrophotometer with a cell compartment kept at constant temperature. The applicability of Beer's law was verified at $261 \mathrm{~nm}$ under the reaction conditions. The molar extinction coefficient, $\varepsilon$, was determined $(\varepsilon=(1.32 \pm$ $0.04) \times 10^{4} \mathrm{dm}^{3} \mathrm{~mol}^{-1} \mathrm{~cm}^{-1}$ ) and was found to be in a good agreement with that reported previously [26]. In addition, there is no interference from other reagents at this wavelength. It was observed that the oxidation reaction did not proceed in the absence of silver(I) catalyst. The pseudofirst order rate constant values of the catalyzed reaction $\left(k_{\mathrm{C}}\right)$ were obtained from the linear portion of $\ln$ (absorbance) versus time plots, which were the average of at least two independent kinetics runs and were reproducible to within $\pm 4 \%$. Double logarithmic plots were used to determine the order with respect to each reactant. The concentration of the particular species being examined was varied while the concentrations of the other species were held fixed.

Time-resolved spectra during the course of the reaction

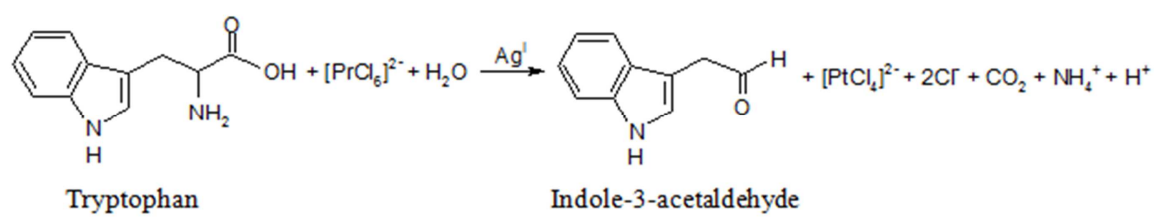

The product aldehyde, indole-3-acetaldehyde, is tested by thin layer chromatography. One spot is obtained when the chromatogram is assayed with 2,4-dinitrophenylhydrazine. An aliquot $(5 \mathrm{ml})$ is pipetted into $50 \mathrm{ml}$ of $2.0 \mathrm{~N} \mathrm{HCl}$ saturated with 2,4-dinitrophenylhydrazine, which is filtered, washed, dried and weighed. The product 2,4-dinitrophenylhydrazone was formed. Further proof of the formation of the aldehyde is obtained by isolating the aldehyde using the between tryptophan and platinum(IV) in the presence of silver(I) catalyst are shown in Figure 1. The scanned spectra indicate gradual disappearance of the $\mathrm{Pt}^{\mathrm{IV}}$ absorption band with time as a result of its reduction. A hyposchromic shift in the $\mathrm{Pt}^{\mathrm{IV}}$ band of about $5 \mathrm{~nm}$ from 261 to $256 \mathrm{~nm}$ as well as two isosbestic points located at 247 and $277 \mathrm{~nm}$ are apparent in the spectra.

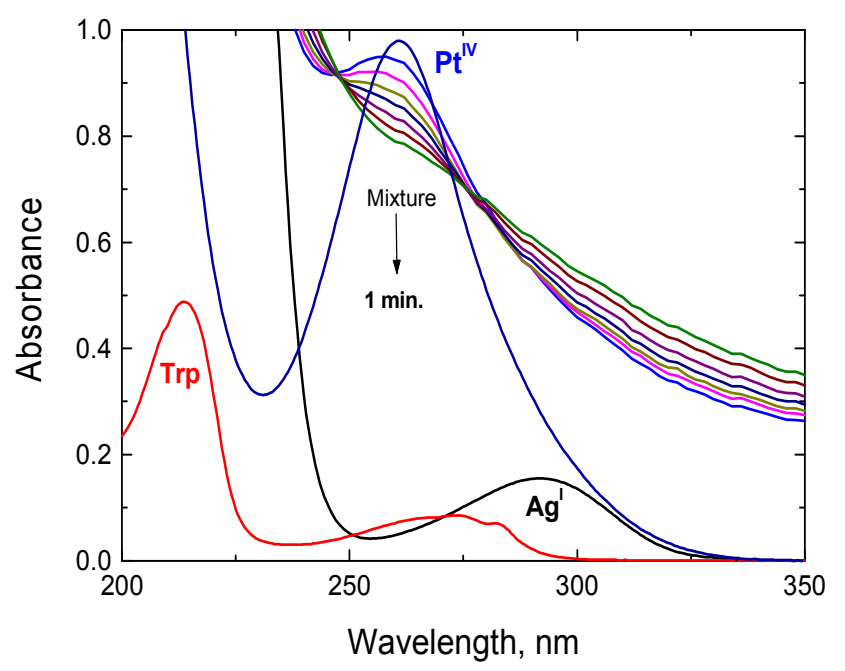

Figure 1. Time-resolved spectra through silver(I)-catalyzed oxidation of tryptophan by platinum(IV) in perchlorate solution. $[\mathrm{Trp}]=4.0 \times 10^{-3},\left[\mathrm{Pt}^{I V}\right]$ $=8.0 \times 10^{-5},\left[\mathrm{H}^{+}\right]=1.0,\left[\mathrm{Ag}^{I}\right]=1.0 \times 10^{-5}$ and $\mathrm{I}=2.0 \mathrm{~mol} \mathrm{dm} \mathrm{m}^{-3}$ at $25^{\circ} \mathrm{C}$.

\section{Results}

\subsection{Stoichiometry and Product Identification}

Different reaction mixtures with different sets of reactants containing various amounts of $\mathrm{Pt}^{\mathrm{IV}}$ and tryptophan at fixed acidity, ionic strength, and temperature were allowed to react for $24 \mathrm{~h}$ in an inert atmosphere. After completion of the reactions, the unreacted $\left[\mathrm{Pt}^{\mathrm{IV}}\right]$ was assayed spectrophotometrically. Results indicated that one mole of the amino acid consumed one mole of $\mathrm{Pt}^{\mathrm{IV}}$ in the predominant reaction, as represented in the following stoichiometric equation: standard method [27]. The byproducts are identified as ammonia and carbon dioxide by Nessler's reagent [28] and lime water, respectively. Similar oxidation products with different experimental conditions have been reported earlier [7-9]. On the other hand, formation of $\left[\mathrm{Pt}^{\mathrm{II}} \mathrm{Cl}_{4}\right]^{2-}$ was confirmed [29] by the observed black precipitate of platinum(II) hydroxide on addition of alkali to the reaction mixture, according to the reaction, 


$$
\left[\mathrm{PtCl}_{4}\right]^{2-}+2 \mathrm{OH}^{-}=\mathrm{Pt}(\mathrm{OH})_{2}+4 \mathrm{Cl}^{-}
$$

\subsection{Effect of [Platinum(IV)] on the Oxidation Rate}

The concentration of the oxidant, platinum(IV), was varied in the range of $2.0 \times 10^{-5}$ to $14.0 \times 10^{-5} \mathrm{~mol} \mathrm{dm}^{-3}$ at constant $[\operatorname{Trp}],\left[\mathrm{Ag}^{\mathrm{I}}\right],\left[\mathrm{H}^{+}\right]$, ionic strength and temperature. The nonvariation in the observed first order rate constants at various concentrations of $\mathrm{Pt}^{\mathrm{IV}}$ (Table 1) indicates that the order with respect to the oxidant is confirmed to be one.

Table 1. Effect of variation of $\left[\mathrm{Pt}^{I V}\right],[\mathrm{Trp}],\left[\mathrm{H}^{+}\right],\left[\mathrm{Ag}^{I}\right]$ and ionic strength, I, on the observed first order rate constant $\left(k_{C}\right)$ in the silver(I)-catalyzed oxidation of tryptophan by platinum(IV) in perchlorate solutions at $25^{\circ} \mathrm{C}$.

\begin{tabular}{|c|c|c|c|c|c|}
\hline $\begin{array}{l}10^{5} \\
{\left[\mathrm{Pt}^{\mathrm{IV}}\right](\mathrm{mol}} \\
\left.\mathrm{dm}^{-3}\right) \\
\end{array}$ & $\begin{array}{l}10^{3} \\
{[\operatorname{Trp}](\mathrm{mol}} \\
\left.\mathrm{dm}^{-3}\right) \\
\end{array}$ & $\begin{array}{l}{\left[\mathrm{H}^{+}\right](\mathrm{mol}} \\
\left.\mathrm{dm}^{-3}\right)\end{array}$ & $\begin{array}{l}10^{5} \\
{\left[\mathrm{Ag}^{\mathrm{I}}\right](\mathrm{mol}} \\
\left.\mathrm{dm}^{-3}\right) \\
\end{array}$ & $\begin{array}{l}I(\mathrm{~mol} \\
\left.\mathrm{dm}^{-3}\right)\end{array}$ & $10^{5} k_{\mathrm{C}}\left(\mathrm{s}^{-1}\right)$ \\
\hline 2.0 & 4.0 & 1.0 & 1.0 & 2.0 & 33.1 \\
\hline 4.0 & 4.0 & 1.0 & 1.0 & 2.0 & 33.9 \\
\hline 6.0 & 4.0 & 1.0 & 1.0 & 2.0 & 34.3 \\
\hline 8.0 & 4.0 & 1.0 & 1.0 & 2.0 & 33.2 \\
\hline 10.0 & 4.0 & 1.0 & 1.0 & 2.0 & 32.7 \\
\hline 12.0 & 4.0 & 1.0 & 1.0 & 2.0 & 31.9 \\
\hline 14.0 & 4.0 & 1.0 & 1.0 & 2.0 & 33.4 \\
\hline 8.0 & 1.0 & 1.0 & 1.0 & 2.0 & 16.3 \\
\hline 8.0 & 2.0 & 1.0 & 1.0 & 2.0 & 23.1 \\
\hline 8.0 & 4.0 & 1.0 & 1.0 & 2.0 & 33.2 \\
\hline 8.0 & 6.0 & 1.0 & 1.0 & 2.0 & 42.0 \\
\hline 8.0 & 8.0 & 1.0 & 1.0 & 2.0 & 49.8 \\
\hline 8.0 & 10.0 & 1.0 & 1.0 & 2.0 & 56.2 \\
\hline 8.0 & 12.0 & 1.0 & 1.0 & 2.0 & 63.9 \\
\hline 8.0 & 4.0 & 0.4 & 1.0 & 2.0 & 19.2 \\
\hline 8.0 & 4.0 & 0.6 & 1.0 & 2.0 & 24.1 \\
\hline 8.0 & 4.0 & 0.8 & 1.0 & 2.0 & 28.8 \\
\hline 8.0 & 4.0 & 1.0 & 1.0 & 2.0 & 33.2 \\
\hline 8.0 & 4.0 & 1.3 & 1.0 & 2.0 & 40.2 \\
\hline 8.0 & 4.0 & 1.6 & 1.0 & 2.0 & 46.7 \\
\hline 8.0 & 4.0 & 2.0 & 1.0 & 2.0 & 52.4 \\
\hline 8.0 & 4.0 & 1.0 & 0.2 & 2.0 & 7.8 \\
\hline 8.0 & 4.0 & 1.0 & 0.5 & 2.0 & 17.4 \\
\hline 8.0 & 4.0 & 1.0 & 1.0 & 2.0 & 33.2 \\
\hline 8.0 & 4.0 & 1.0 & 1.5 & 2.0 & 46.2 \\
\hline 8.0 & 4.0 & 1.0 & 2.0 & 2.0 & 59.8 \\
\hline 8.0 & 4.0 & 1.0 & 2.5 & 2.0 & 60.7 \\
\hline 8.0 & 4.0 & 1.0 & 3.0 & 2.0 & 81.0 \\
\hline 8.0 & 4.0 & 1.0 & 1.0 & 2.0 & 33.2 \\
\hline 8.0 & 4.0 & 1.0 & 1.0 & 2.4 & 30.7 \\
\hline 8.0 & 4.0 & 1.0 & 1.0 & 2.8 & 28.4 \\
\hline 8.0 & 4.0 & 1.0 & 1.0 & 3.2 & 25.0 \\
\hline 8.0 & 4.0 & 1.0 & 1.0 & 3.6 & 22.7 \\
\hline 8.0 & 4.0 & 1.0 & 1.0 & 4.0 & 19.2 \\
\hline 8.0 & 4.0 & 1.0 & 1.0 & 4.5 & 17.8 \\
\hline
\end{tabular}

Experimental Error $\pm 3 \%$

\subsection{Effect of [Tryptophan] on the Oxidation Rate}

The observed first order rate constant $\left(k_{\mathrm{C}}\right)$ was determined at different initial concentrations of the reductant tryptophan keeping all other reactants concentration constant including sliver(I) catalyst. The results showed that the rate constant increased with increase in the tryptophan concentration as listed in Table 1. A plot of $k_{\mathrm{C}}$ versus [Trp] was found to be linear with a positive intercept confirming fractional-first order dependence with respect to the amino acid (Figure not shown).

\subsection{Effect of $\left[\mathrm{H}^{+}\right]$on the Oxidation Rate}

The reaction rate was measured at constant $[\mathrm{Trp}],\left[\mathrm{Pt}^{\mathrm{IV}}\right]$, $\left[\mathrm{Ag}^{\mathrm{I}}\right]$, ionic strength and temperature but with various $\left[\mathrm{H}^{+}\right]$ $\left(0.4-2.0 \mathrm{~mol} \mathrm{dm}^{-3}\right)$. The rate of reaction was found to increase as $\left[\mathrm{H}^{+}\right]$increased with less than unit order as found from the plot of $\log k_{\mathrm{C}}$ versus $\log \left[\mathrm{H}^{+}\right]$(Figure not shown).

\subsection{Effect of [Ag'] Catalyst}

The reaction rate was measured with various $\left[\mathrm{Ag}^{\mathrm{I}}\right],(0.2-$ 3.0) $\times 10^{-5}$ moldm $^{-3}$ at constant other variables. The reaction rate increased with increase in $\left[\mathrm{Ag}^{\mathrm{I}}\right]$ (Table 1). The order with respect to $\left[\mathrm{Ag}^{\mathrm{I}}\right]$ was unity as found from the plot of log $k_{\mathrm{C}}$ versus $\log \left[\mathrm{Ag}^{\mathrm{I}}\right]$ (Figure 2).

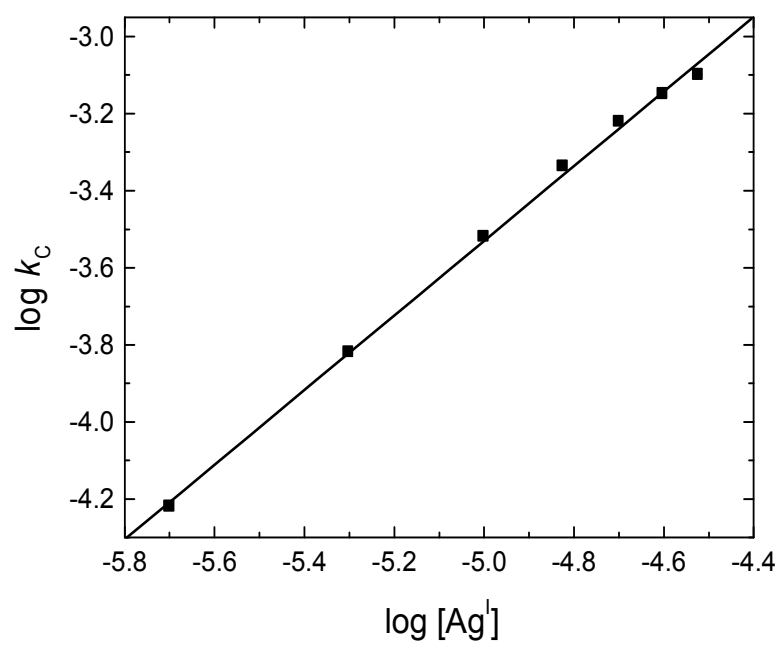

Figure 2. Plot of $\log k_{C}$ versus $\log \left[\mathrm{Ag}^{I}\right]$ in the silver(I)-catalyzed oxidation of tryptophan by platinum(IV) in perchlorate solutions. $[\operatorname{Trp}]=4.0 \times 10^{-3}$, $\left[P t^{I V}\right]=8.0 \times 10^{-5},\left[H^{+}\right]=1.0$ and $I=2.0$ moldm $^{-3}$ at $25^{\circ} \mathrm{C}$.

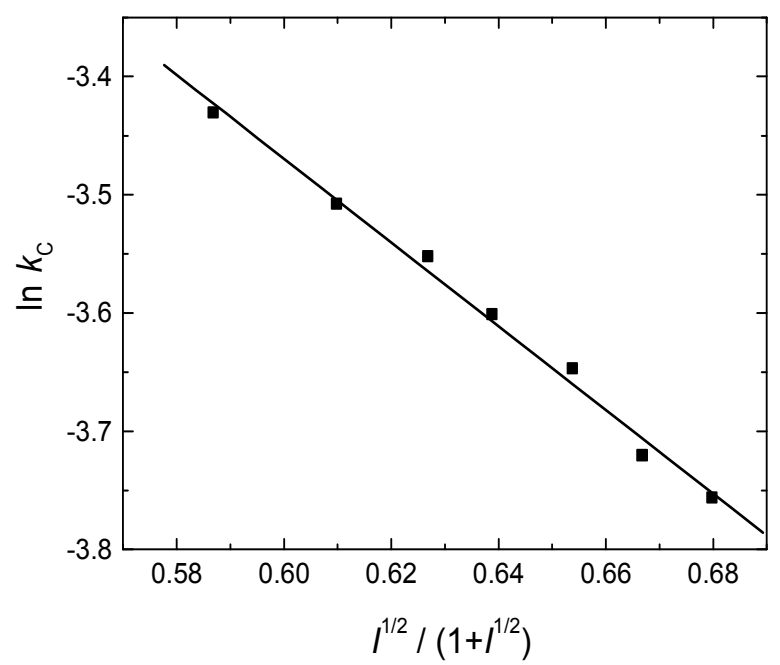

Figure 3. Debye-Hückel plots in the silver(I)-catalyzed oxidation of tryptophan by platinum (IV) in perchlorate solutions. $[\operatorname{Trp}]=4.0 \times 10^{-3}$, $\left[P t^{I V}\right]=8.0 \times 10^{-5}$ and $\left[\mathrm{H}^{+}\right]=1.0 \mathrm{moldm}^{-3}$ at $25^{\circ} \mathrm{C}$. 


\subsection{Effect of Ionic Strength and Dielectric Constant}

The effect of ionic strength on the oxidation rate was studied by the addition of sodium perchlorate to the reaction medium at constant concentration of tryptophan, $\mathrm{Pt}^{\mathrm{IV}}$ and $\mathrm{Ag}^{\mathrm{I}}$, and at constant $\mathrm{pH}$ and temperature. The results are presented in Table 1. These results showed that the rate constant decreased with increase in the ionic strength of the medium, and the Debye-Hückel plot was found to be linear with a negative slope as shown in Figure 3.

In order to determine the effect of the dielectric constant $(D)$ of the medium on the oxidation rate, the oxidation of tryptophan by $\mathrm{Pt}^{\mathrm{IV}}$ was studied at different solvent compositions $(\mathrm{v} / \mathrm{v})$ of acetic acid and water. The dielectric constant of the medium at different compositions was calculated using the dielectric constants of water and acetic acid as 78.5 and 6.15 , respectively, at $25^{\circ} \mathrm{C}$. The rate constant was found to increase with the decrease in dielectric constant of the solvent mixture, i.e., increase in acetic acid content. The plot of $\log k_{\mathrm{C}}$ versus $1 / D$ was found to be linear with a positive slope as shown in Figure 4.

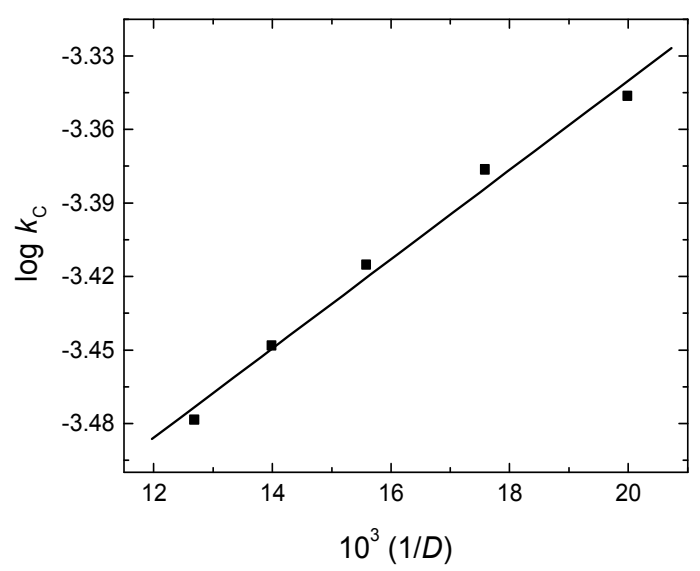

Figure 4. Effect of solvent composition on the observed first order rate constant. Plot of $\log k_{C}$ versus 1/D for the silver(I)-catalyzed oxidation of tryptophan by platinum(IV) in perchlorate solutions. $\left[\right.$ Trp] $=4.0 \times 10^{-3}$, $\left[\mathrm{Pt}^{I V}\right]=8.0 \times 10^{-5},\left[\mathrm{H}^{+}\right]=1.0$ and $\mathrm{I}=2.0$ moldm $^{-3}$ at $25^{\circ} \mathrm{C}$.

\section{Discussion}

Amino acids are known [30] to exist in zwitterionic forms in equilibrium with anionic and cationic forms, depending upon $\mathrm{pH}$ of the solution according to the following equilibria:

$$
\begin{aligned}
& \mathrm{RCH}\left(\mathrm{NH}_{2}\right) \mathrm{COO}^{-} \frac{\mathrm{H}^{+}}{=} \mathrm{RCH}\left({ }^{+} \mathrm{NH}_{3}\right) \mathrm{COO}^{-} \frac{\mathrm{H}^{+}}{\overline{K_{1}}} \mathrm{RCH}\left({ }^{+} \mathrm{NH}_{3}\right) \mathrm{COOH} \\
& \text { anionic form } \\
& \text { (zwitterion) } \\
& \text { cationic form }
\end{aligned}
$$

where $K_{1}$ is the protonation constant of the amino acid.

Under the present experimental conditions and the observed enhancement of the reaction rate upon increasing acid concentration, the protonated form of the amino acid may be the reactive species in the rate-determining step, which plays the main role in the reaction kinetics. On the other hand, amino acids form an adduct with $\mathrm{Ag}^{\mathrm{I}}$ catalyst [12, $13,16]$ owing to the availability of the electron pairs on both oxygen atom of the carboxylate group and nitrogen atom of the amine group. Within the protolytic amino acid system, the carboxylate and amine groups may act as nucleophiles, depending on $\mathrm{pH}$ of the medium. The protolyticgroup with the highest basicity interacts with the silver(I) catalyst. Thus, at low $\mathrm{pH}$ where the amine group is protonated, the carboxylate group should be able to attack $\mathrm{Ag}^{\mathrm{I}}$.

It is also reported [31] that the platinum(IV) species in acid medium is present as $\left[\mathrm{PtCl}_{6}\right]^{2-}$, which is assumed to be the principal reactive oxidant. The reduction of $\left[\mathrm{PtCl}_{6}\right]^{2-}$ generally proceeds as follows:

$$
\left[\mathrm{PtCl}_{6}\right]^{2-}+2 \mathrm{e}^{-}=\left[\mathrm{PtCl}_{4}\right]^{2-}+2 \mathrm{Cl}^{-}
$$

In this reduction process, octahedral $\mathrm{Pt}^{\mathrm{IV}}$ is reduced to square planar $\mathrm{Pt}^{\mathrm{II}}$ with release of two $\mathrm{Cl}^{-}$ions. Therefore, this reaction is better classified as a reductive-elimination reaction [32, 33]. Because platinum(IV) complexes are generally substitution-inert [34], initial complex formation between platinum(IV) and reductant prior to electron transfer can be excluded in reductive-elimination reactions.

Two alternative reaction mechanisms for the oxidation of amino acids by platinum(IV) may be considered. The first mechanism involves a simultaneous two-electron transfer in a single step. The second mechanism involves two successive one-electron transfer steps. If the transition states of the reductant and/or oxidant are unstable, a simultaneous twoelectron transfer mechanism may be suggested, such as that in the oxidation of uranium(IV) by $\left[\mathrm{PtCl}_{6}\right]^{2-}[35]$. In the present study, addition of acrylonitrile monomer to the reaction mixture failed to give polymerized products. It may be that a free radical such as the $\mathrm{Pt}^{\mathrm{III}}$ species is too short-lived to interact with acrylonitrile to give the polymerized product under our experimental conditions. Consequently, the twoelectron transfer mechanism seems plausible.

\section{Reaction Mechanism}

The reaction between platinum(IV) and tryptophan in the presence of small amounts of silver(I) catalyst has a stoichiometry of 1:1 with a first order dependence on both $\left[\mathrm{Pt}^{\mathrm{IV}}\right]$ and $\left[\mathrm{Ag}^{\mathrm{I}}\right]$, and less than unit order with respect to [Trp]. The rate of reduction of platinum(IV) increases with decreasing $\mathrm{pH}$ with fractional-first order dependence on $\left[\mathrm{H}^{+}\right]$, suggesting that amino acid substrate is first subjected to protonation in a prior rate-determining step. The rate of reaction decreased on increasing the ionic strength and dielectric constant of the medium, suggesting that the reaction occurred between two ions with opposite charges [36-39].

The less than unit order with respect to [Trp] suggests formation of an intermediate complex between the catalyst silver(I) and amino acid substrate prior to the reaction with the oxidant. Complex formation was proved kinetically by a non-zero intercept of the plot of $\left[\mathrm{Ag}^{\mathrm{I}}\right] / k_{\mathrm{C}}$ versus $1 /[\operatorname{Trp}]$ (Figure 5). Spectroscopic evidence to support complex formation between $\mathrm{Ag}^{\mathrm{I}}$ and tryptophan which obtained from the UV-Vis spectra of platinum(IV) is the observed hyposchromic shift in the wavelength with appearance of two isosbestic points as shown in Figure 1. 
The experimental results suggested that the protonated amino acid combines with $\mathrm{Ag}^{\mathrm{I}}$ to form an intermediate complex, $[\operatorname{Trp}-\mathrm{Ag}]^{2+}(\mathrm{C})$, which then reacts in a slow step with one mole of platinum(IV) to give rise to the products with regeneration of the catalyst $\mathrm{Ag}^{\mathrm{I}}$, as illustrated by the following sequence:

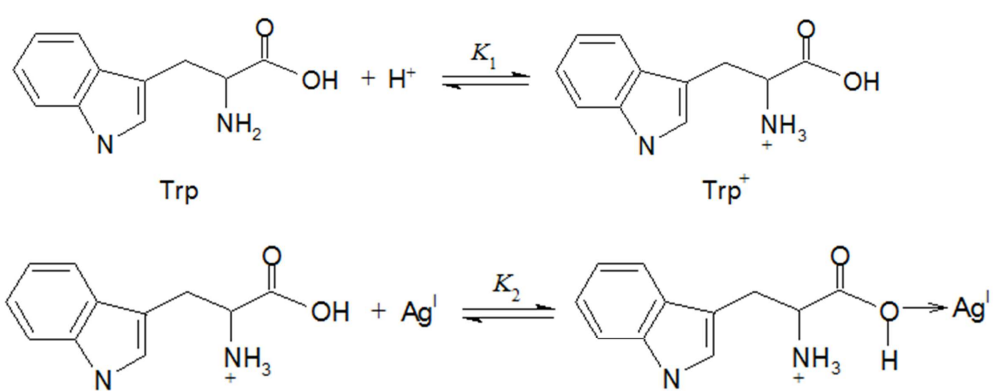

(C)

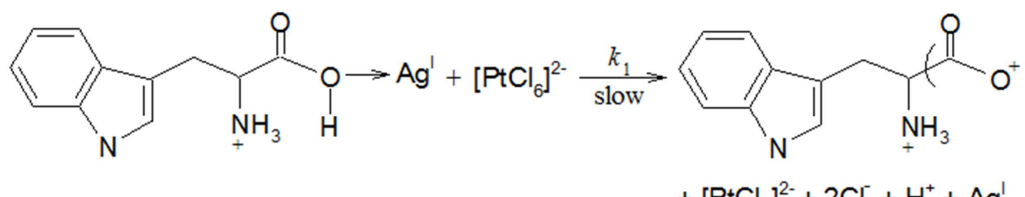
$+\left[\mathrm{PtCl}_{4}\right]^{2-}+2 \mathrm{Cl}^{-}+\mathrm{H}^{+}+\mathrm{Ag}^{\prime}$<smiles></smiles><smiles></smiles>

The suggested mechanism leads to the following rate law:

$$
\text { Rate }=\frac{-d\left[\mathrm{Pt}^{\mathrm{IV}}\right]}{d t}=\frac{+d[\mathrm{C}]}{d t}=k_{1}[\mathrm{C}]\left[\mathrm{Pt}^{\mathrm{IV}}\right]
$$

The relationship between the rate of complex formation and the substrate, hydrogen ion, catalyst and oxidant concentrations can be deduced to give the following rate-law expression:

$$
\text { Rate }=\frac{k_{1} K_{1} K_{2}[\operatorname{Trp}]\left[\mathrm{H}^{+}\right]\left[\mathrm{Ag}^{\mathrm{I}}\right]\left[\mathrm{Pt}^{\mathrm{IV}}\right]}{\left(1+K_{1}\left[\mathrm{H}^{+}\right]+K_{1} K_{2}\left[\mathrm{H}^{+}\right]\left[\mathrm{Ag}^{\mathrm{I}}\right]\right)\left(1+K_{1} K_{2}[\operatorname{Trp}]\left[\mathrm{H}^{+}\right]\right)}
$$

In view of low concentration of $\left[\mathrm{Ag}^{\mathrm{I}}\right]$ used, the term $K_{1} K_{2}\left[\mathrm{H}^{+}\right]\left[\mathrm{Ag}^{\mathrm{I}}\right]$ in the denominator can be neglected. Therefore, Eq. (7) becomes,

$$
\text { Rate }=\frac{k_{1} K_{1} K_{2}[\mathrm{Trp}]\left[\mathrm{H}^{+}\right]\left[\mathrm{Ag}^{\mathrm{I}}\right]\left[\mathrm{Pt}^{\mathrm{IV}}\right]}{\left(1+K_{1}\left[\mathrm{H}^{+}\right]\right)\left(1+K_{1} K_{2}[\operatorname{Trp}]\left[\mathrm{H}^{+}\right]\right)}
$$

Under pseudo-first order condition,

$$
\text { Rate }=\frac{-d\left[\mathrm{Pt}^{\mathrm{IV}}\right]}{d t}=k_{\mathrm{C}}\left[\mathrm{Pt}^{\mathrm{IV}}\right]
$$

Comparing Eqs. (8) and (9) and rearrangement, we obtain,

$$
\frac{\left[\mathrm{Ag}^{\mathrm{I}}\right]}{k_{C}}=\left(\frac{1+K_{1}\left[\mathrm{H}^{+}\right]}{k_{1} K_{1} K_{2}\left[\mathrm{H}^{+}\right]}\right) \frac{1}{[\operatorname{Trp}]}+K^{,}
$$

where, $K^{\prime}=\left(1+K_{1}\left[\mathrm{H}^{+}\right]\right) / k_{1}$.

According to Eq. (10), the plots of $\left[\mathrm{Ag}^{\mathrm{I}}\right] / k_{\mathrm{C}}$ against $1 /[\mathrm{Trp}]$, at constant $\left[\mathrm{H}^{+}\right]$, and $\left[\mathrm{Ag}^{\mathrm{I}}\right] / k_{\mathrm{C}}$ against $1 /\left[\mathrm{H}^{+}\right]$, at constant [Trp], should be linear with positive intercepts on $\left[\mathrm{Ag}^{\mathrm{I}}\right] / k_{\mathrm{C}}$ axes. The experimental results satisfied this requirement as shown in Figure 5.

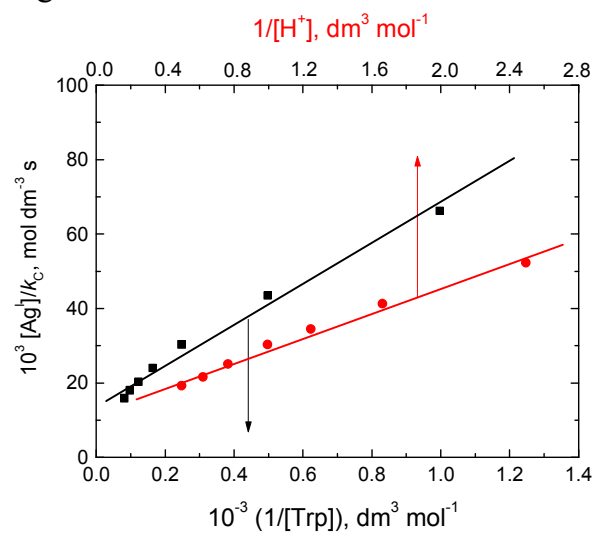

Figure 5. Verification of the rate law (8) in the form of equation (10) in the silver(I)-catalyzed oxidation of tryptophan by platinum(IV) in perchlorate solutions. $\left[P t^{I V}\right]=8.0 \times 10^{-5}$ and $I=2.0 \mathrm{~mol} \mathrm{dm} m^{-3}$ at $25^{\circ} \mathrm{C}$. 


\section{Conclusion}

The reaction between tryptophan and platinum(IV) in perchlorate solutions did not proceed in the absence of the catalyst. The suggested mechanism for oxidation involves formation of a silver(I)-tryptophan intermediate complex in a pre-equilibrium step, which reacts with the oxidant by an inner-sphere mechanism leading to decomposition of the complex in the rate-determining step. The final oxidation products of tryptophan were identified as indole-3acetaldehyde, ammonium ion and carbon dioxide.

\section{References}

[1] Senagar SKS, Yadav BS (1988)Kinetics and mechanism of copper(II)-catalyzed oxidation of asparagine by sodium $\mathrm{N}$ chloro-p-toluene sulphonamide in alkaline media, J. Indian Chem. Soc. 65: 88-90.

[2] Sanjeevagowda TP, Mahantesh AA, Abdulazizkhan LH (2008) Oxidative deamination and decarboxylation of L-asparagine by the aqueous alkaline diperiodato-nickelate(IV) complex, J. Solution Chem. 37: 1795-180.

[3] Khalid MAA (2007) Oxidative kinetics of amino acids by peroxydisulfate: Effect of dielectric constant, Arabian J. Sci. Eng. 33: 199-210.

[4] Anweting IB, Iyun JF, Idris SO (2012) Kinetics and mechanistic approach to the oxidation of L-tryptophan by permanganate ion in aqueous acidic medium. Adv. Appl. Sci. Res. 3: 3401-3409.

[5] Sharma VK, Sharma K, Tiwari PS, Khare D (2011)Mechanism of quinquevalent vanadium oxidation of Ltyptophan in sulphuric acid medium. Int. J. Pharm. Life Sci. 2: 1223-1225.

[6] Shetti NP, Hosamani RR, Nandibewoor ST (2009) Kinetic and mechanistic investigations on oxidation of L-tryptophan by diperiodatocuprate (III) in aqueous alkaline medium. Open Catal. J. 2: 130-139.

[7] Asghar BH, Altass HM, Fawzy A (2015) Copper(II) catalysis for oxidation of L-tryptophan by hexacyanoferrate(III) in alkaline medium: a kinetic and mechanistic approach, J. Saudi.Chem. Soc. in press.

[8] Fawzy A (2015) Palladium(II)-catalyzed oxidation of Ltryptophan by hexacyanoferrate(III) in perchloric acid medium: a kinetic and mechanistic approach. J. Chem. Sci.in press.

[9] Fawzy A, Ashour SS, Musleh MA, Hassan RM, Asghar BH (2015) Kinetics and mechanistic approach to the chromic acid oxidation of L-tryptophan with a spectral detection of chromium(III) product, J. Saudi Chem. Soc. in press.

[10] Fawzy A (2014) Influence of copper(II) catalyst on the oxidation of L-histidine by platinum(IV) in alkaline medium: A kinetic and mechanistic study. Transition Met. Chem. 39: 567-576.

[11] Fawzy A (2015)Kinetics and mechanistic approach to the oxidative behavior of biological anticancer platinum(IV) complex towards L-asparagine in acid medium and the effect of copper(II) catalyst, Int. J. Chem. Kinet. 47: 1-12.
[12] Fawzy A, Asghar BH (2015) Kinetics and mechanism of uncatalyzed and silver(I)-catalyzed oxidation of L-histidine by hexachloroplatinate(IV) in acid medium, Transition Met. Chem. 40: 287-295.

[13] Asghar BH, Altass HM, Fawzy A (2015) Transition metal ions-catalyzed oxidation of L-asparagine by platinum(IV) in acid medium: akinetic and mechanistic study. Transition Met. Chem. 40: 587-594.

[14] Fawzy A, Zaafarany IA (2015) Kinetic and mechanistic investigation on the zirconium(IV)-catalyzed oxidation of Lhistidine by hexachloroplatinate(IV) in acid medium. Chem. Sci. Rev. Lett. 4: 608-618.

[15] Fawzy A, Zaafarany IA (2015) Mechanistic investigation of copper(II)-catalyzed oxidation of L-asparagine by hexachloroplatinate(IV) in aqueous alkaline medium: akinetic approach.J. Multidisc. Eng. Sci. Technol. 2: 1038-1045.

[16] Asghar BH, Altass HM, Fawzy A (2016) Silver(I)-catalysis of oxidative deamination and decarboxylation of L-asparagine and L-histidine by platinum(IV) in perchloricacid solutions: acomparative kinetics study. J. Env. Chem. Eng.4:617-623.

[17] Fawzy A, Ashour SS, Musleh MA (2014) Base-catalyzed oxidation of L-asparagine by alkaline permanganate and the effect of alkali-metal ion catalysts: Kinetics and mechanistic approach, React. Kinet.Mech. Catal. 111: 443-460.

[18] Fawzy A, Ashour SS, Musleh MA (2014) Kinetics and mechanism of oxidation of L-histidine by permanganate ions in sulfuric acid medium, Int. J. Chem. Kinet. 46: 370-381.

[19] Keage MC, Kelland MJ, Neidles LR, Warning MJ, ed. (1993) Molecular Aspects of Anticover Drug DNA Interactions, vol. 1, CRC Press, New York, NY, USA.

[20] Lemma K, Sargeson A, Elding LI (2000) Kinetics and mechanism for reduction of oral anticancer platinum(IV) dicarboxylate compounds by L-ascorbate ions, J. Chem. Soc. Dalton Trans. 7: 1167-1172.

[21] Lemma K, Shi T, Elding LI (2000) Kinetics and mechanism for reduction of the anticancer prodrug trans, trans, trans$\left[\mathrm{PtCl}_{2}(\mathrm{OH})_{2}\left(\mathrm{c}-\mathrm{C}_{6} \mathrm{H}_{11} \mathrm{NH}_{2}\right)\left(\mathrm{NH}_{3}\right)\right]$ (JM335) by thiols, Inorg. Chem. 39: 1728-1734.

[22] Weiss RP, Christian MC (1993) Newcisplatin analogues in development. A review.Drugs 46: 360-377.

[23] Beattie K, Basolo F (1967) Reduction of some platinum(IV) complexes with tris(bipyridine) chromium(II) ion, Inorg. Chem. 6: 2069-2073.

[24] Beattie K, Basolo F (1971) Two-electron inner-sphere reduction of chloropentaammine-platinum(IV) ion by aquochromium(II) ion, Inorg. Chem. 10: 486-491.

[25] Moodley KG, Nicol MJ (1977) Kinetics of the reduction of platinum(IV) by tin(II) and copper(I) in aqueous chloride solutions, J. Chem. Soc., Dalton Trans. 239-243.

[26] Georgieva M, Andonovski B (2003) Determination of platinum(IV) by UV spectrophotometry, Anal. Bioanal. Chem. 375: 836-839.

[27] Vogel AI (1973) Text book of practical organic chemistry, third ed., ELBS Longman, London, 1973, p. 332 and 679. 
[28] Ghosh MV, Reed JW, Bose RN, Gould ES (1994) Electron transfer. 118. Proton-coupled reductions of a dinuclear dimanganese (III, IV) model for the reactive center in photosystem II.Inorg. Chem. 33: 73-78.

[29] Pal B, Sen Gupta KK (2000) Kinetics and mechanism of hexachloroplatinate(IV) reduction by some neutralized alphahydroxy acids in a carbonate-hydrogencarbonate buffer medium, Bull. Chem. Soc. Japan. 73: 553-560.

[30] Martell AE, Smith RM (1974) In: Critical Stability Constants. vol. I. Plenum Press, New York, pp. 321.

[31] Kramer J, Koch KR (2006) ${ }^{195} \mathrm{Pt}$ NMR Study of the speciation and preferential extraction of $\mathrm{Pt}(\mathrm{IV})$-mixed halide complexes by diethylenetriamine-modified silica-based anion exchangers, Inorg. Chem. 45: 7843-7855.

[32] Lemma K, Sargeson A, Elding LI (2000) Kinetics and mechanism for reduction of oral anticancer platinum(IV) dicarboxylate compounds by L-ascorbate ions, J. Chem. Soc. Dalton Trans. 7: 1167-1172.
[33] Lemma K, Shi T, Elding LI (2000) Kinetics and mechanism for reduction of the anticancer prodrug trans, trans, trans$\left[\mathrm{PtCl}_{2}(\mathrm{OH})_{2}\left(\mathrm{c}-\mathrm{C}_{6} \mathrm{H}_{11} \mathrm{NH}_{2}\right)\left(\mathrm{NH}_{3}\right)\right]$ (JM335) by thiols, Inorg. Chem. 39: 1728-1734.

[34] Mason WR (1972) Platinum(II)-catalyzed substitutions of platinum(IV) complexes, Coord. Chem. Rev.7: 241-255.

[35] Hassan RM, Kojima T, Fukutomi T (1982) Kinetics of the oxidation of uranium(IV) by hexachloroplatinate(IV) in aqueous solution. VI International symposium on solutesolute-solvent interactions. Japan, pp. 113.

[36] Amis ES (1966) Solvent Effect on Reaction Rates and Mechanism, Academic Press, New York, pp. 28.

[37] Frost AA, Person RG (1970) Kinetics and mechanism, Wiley Eastern, New Delhi, pp. 147.

[38] Rochester CH (1971) Progress in Reaction Kinetics. Pergamon Press, Oxford, 1971, pp. 145.

[39] Laidler K (1965) Chemical Kinetics. McGraw-Hill, New York. 